\title{
VARIAÇÃO SOMACLONAL EM MUDAS MICROPROPAGADAS DE BANANEIRA, CULTIVAR PACOVAN ${ }^{(1)}$
}

\author{
CYNTHIA CHRISTINA CARVALHO DOS SANTOS(2); PAULO HERCÍLIO \\ VIEGAS RODRIGUES ${ }^{(3)}$
}

\begin{abstract}
RESUMO
A literatura tem relatado a ocorrência de variação somaclonal em plantas derivadas de cultura de tecidos. Neste trabalho, foi estudada a influência do número de subcultivos na indução de variantes em bananeira, cultivar Pacovan (Musa spp., grupo AAB). Ápices caulinares foram introduzidos e multiplicados in vitro, utilizando-se no estabelecimento o meio de cultura MS com adição de 2,5 mg. $\mathrm{L}^{-1}$ de BAP e nos subcultivos subseqüentes, o meio MS com $4,0 \mathrm{mg} \cdot \mathrm{L}^{-1}$ de BAP para indução de brotações laterais. Foram obtidas gerações com diferentes números de subcultivos $(3,4,5,6,7,8$ e 9), e comparadas com mudas obtidas de rizomas. Observaram-se as plantas obtidas, no total de 426 , em condições de campo no Vale do Açu (RN). Para cálculo da porcentagem de variantes somaclonais, avaliaram-se as seguintes características morfológicas: estatura da planta, coloração e forma das folhas e conformação do cacho. Foram consideradas como variantes apenas as plantas cujos perfilhos também mostravam o mesmo tipo de variação. Constatou-se a ocorrência de variação somaclonal nas mudas provenientes dos tratamentos a partir de cinco subcultivos, atingindo-se o valor de $5,8 \%$ de variantes no nono subcultivo. O aumento da porcentagem de variação somaclonal com o do número de subcultivos indica o cuidado que as biofábricas devem ter em relação a esse parâmetro, desenvolvendo protocolos de micropropagação específicos para cada cultivar a ser comercializada.
\end{abstract}

Palavras-chave: produção de mudas, Musa spp, in vitro, variação somaclonal.

\section{ABSTRACT \\ SOMACLONAL VARIATION EVENT ON MICROPROPAGATED PACOVAN BANANA SEEDLING (Musa spp. AAB group)}

The occurrence of somaclonal variation for plants in developed from tissue culture is well documented in the literature. The present study evaluated the influence of numbers subculture in the induction of variants in Pacovan banana tree (Musa spp., AAB group). Apex stems were introduced and multiplied in vitro using culture media MS, with addition of $2.5 \mathrm{mg} \cdot \mathrm{L}^{-1}$ of BAP. In subsequent subcultures, MS with $4.0 \mathrm{mg} \cdot \mathrm{L}^{-1}$ of BAP was used to induce side buds. Results showed that plants were regenerated with different numbers of subculture $(3,4,5,6,7,8$, and 9). These data were compared with seedlings from developed rhizomes. All the plants, were observed at field conditions in Vale do Açu, Rio Grande do Norte State. The percentage of somaclonal variants, some was estimated using morphological characteristics, such as plant size, color and shape of leaves and bunch shape. Only plants in which buds

(1) Recebido para publicação em 3 de fevereiro de 2003 e aceito em 15 de abril de 2004.

$\left({ }^{2}\right)$ Departamento de Biologia Celular e Genética, Universidade Federal do Rio Grande do Norte, Av. Senador Salgado Filho, Campus Universitário, Lagoa Nova, BR 101, 59078-970 Natal (RN).

$\left({ }^{3}\right)$ Laboratório de Cultura de Tecidos Vegetais (PPGBMG/UFRN/BioCampo, Alameda das mansões, 1.178, Candelária, 59067-000 Natal (RN). E-mail: phrviegas@hotmail.com 
showed the same type of variation were considered as variables. Somaclonal variation occurred from the fifth subculture, and on the $9^{\text {th }}$ subculture a $5.8 \%$ variation was observed. The increase of percentage of somaclonal variation, due to a higher number of subcultures, indicates the necessity of protocols for micropropagation specific for each variety to be commercialized.

Key words: seedling production, banana, in vitro, somaclonal variation.

\section{INTRODUÇÃO}

Com a utilização da técnica de micropropagação, mudas de bananeira provenientes de cultura de tecidos são produzidas e colocadas à disposição do agricultor. Ainda hoje, a falta de domínio dessa tecnologia, para algumas cultivares regionais de bananeira, é responsável pela colocação no mercado de mudas de qualidade duvidosa, trazendo prejuízos aos agricultores devido à ocorrência de alta taxa de variação somaclonal. Segundo KARP (1994), o aparecimento de variações incontroláveis e inexplicáveis, em plantas produzidas por essa tecnologia, é um fator inesperado e indesejado para empresários e agricultores.

Estudos sobre os fatores que podem influenciar a taxa de variação somaclonal no processo de micropropagação, descritos por Scowcroft (1984) e GEORGE e SHERRINGTON (1984), mostraram que o aparecimento de calos em determinada fase do processo de micropropagação, relaciona-se com a taxa de variação somaclonal, bem como períodos prolongados de cultivo in vitro. Foi observada ainda, a diferença na taxa de variação somaclonal em diferentes genótipos de bananeira para um mesmo protocolo de multiplicação, mostrando diferenças de comportamento dos genótipos ao cultivo in vitro.

Com relação ao número de subcultivos in vitro, alguns autores foram enfáticos em afirmar, que se trata de um fator importante no controle da ocorrência de variação somaclonal. REUVENI et al. (1986) sugeriram que o número máximo de plantas obtido a partir de um ápice caulinar deve ser de aproximadamente 1.000 plantas para a cv. Willians (grupo AAA). KRIKORIAN et al. (1993) sem especificar números, sugeriram que possa ocorrer influência do número excessivo de subcultivos in vitro no aumento da taxa de variação somaclonal.

Trabalhando com uma população representativa de bananeira cv. Grande Naine, micropropagadas in vitro, STOVER (1987) encontrou aproximadamente $25 \%$ de plantas atípicas ou variantes. Segundo seus relatos, alguns tipos de variações se manifestaram cinco ou seis meses após o plantio ou a floração. A variação mais comumente encontrada foi com relação ao porte, variando de baixo ao gigantismo. Avaliando as variantes somaclonais com relação à morfologia,
SMITH (1988) encontrou plantas com estatura anormal, de porte baixo ou mini e até gigantismo; as folhas apresentavam forma afilada (característica tetraplóide), coloração variegada semelhante a um mosaico virótico, ondulações laterais e ausência de cerosidade no limbo foliar.

No experimento de campo realizado por VuYlstKe et al. (1996), o desempenho de plantas variantes do grupo $\mathrm{AAB}$ foi avaliada com relação às características agronômicas. Cerca de três de cada quatro variantes apresentavam desenvolvimento inferior ao de plantas normais. A cultivar Nanicão, estudada por RodRIGUEs et al. (1998), no Vale do Ribeira (SP), apresentou aumento da taxa de variação somaclonal com o do número de subcultivos in vitro, ocorrendo as primeiras variantes a partir do nono subcultivo. Nesse trabalho, que avaliou em condições de campo 1.991 mudas produzidas em diferentes subcultivos, foram observados diferentes tipos de variantes somaclonais, sendo o mais comum o VMIF (Variante Morfológica da Inserção da Folha no Pseudocaule) responsável por redução significativa na produção.

O objetivo do presente trabalho foi observar a influência do número de subcultivos durante o processo de multiplicação in vitro, da cultivar Pacovan, na taxa de variação somaclonal em mudas produzidas e destinadas ao plantio comercial.

\section{MATERIAL E MÉTODOS}

O material utilizado como matriz no processo de micropropagação constituiu-se de rizomas (brotos laterais), da cv. Pacovan (grupo AAB). Foram selecionados 20 rizomas, retiradas as folhas externas, até atingir, aproximadamente, $7,0 \mathrm{~cm}$ de comprimento por $2,5 \mathrm{~cm}$ de diâmetro. Os rizomas foram mergulhados em solução de água e hipoclorito de sódio (2\% de cloro ativo), na proporção de $3: 1$, por aproximadamente 25 minutos. Após o tratamento asséptico, os rizomas foram lavados com água destilada estéril (4 vezes), no interior de câmara de fluxo laminar.

Após a assepsia, com o auxílio de pinça e bisturi, isolou-se o ápice caulinar, constituído de duas a três folhas, envolvendo o meristema e um pequeno segmento de rizoma. 
Os ápices caulinares foram submetidos à inoculação em meio de cultura MS (MURASHIGE e SKOOG, 1962), sólido (6,0 g. $\mathrm{L}^{-1}$ de agar), suplementado com vitaminas de MS, sacarose $\left(30,0 \mathrm{~g}\right.$. $\left.\mathrm{L}^{-1}\right), 6$-benziladenina $\left(2,5 \mathrm{mg} . \mathrm{L}^{-1}\right), \mathrm{pH}$ ajustado para 5,8 e incubado à temperatura média de $26{ }^{\circ} \mathrm{C}$ e fotoperíodo de 16 horas de luz.

Os subcultivos dos explantes, para a formação das diferentes gerações a serem testadas no experimento, iniciaram-se com a transferência dos explantes para meio de cultura com sais e vitaminas de MS suplementado com 4,0 mg. $\mathrm{L}^{-1}$ de BAP, para indução de brotações laterais nas mesmas condições de temperatura e fotoperíodo citados anteriormente.

A partir do segundo subcultivo e com a certeza de não ocorrer contaminações, foram selecionados sete ápices caulinares, isolando e subcultivando os explantes, em meio de cultura fresco, ocorrendo subcultivos a intervalos de quatro semanas.

Cada ápice caulinar foi subcultivado um número predeterminado de vezes formando tratamentos com 3, 4, 5, 6, 7, 8 e 9 subcultivos, cujas plantas obtidas durante o processo foram utilizadas para indução de novas brotações.

À medida que o número de subcultivos de cada geração foi sendo atingido, as plântulas foram transferidas para frascos contendo meio de cultura de enraizamento, constituído de meio de cultura básico, com metade da concentração de sais de MS, sólido $(6,0$ g.L. ${ }^{-1}$ de agar), vitaminas MS, sacarose $\left(30,0\right.$ g. $\left.\mathrm{L}^{-1}\right)$ e de IBA (ácido indolbutírico) $0,2 \mathrm{mg} . \mathrm{L}^{-1}$, onde permaneceram por aproximadamente 20 dias, ou até atingirem enraizamento e alongamento satisfatórios.

Depois de atingirem o estádio desejado (7,0 a $10,0 \mathrm{~cm})$, as plântulas foram transferidas para caixas plásticas contendo vermiculita e mantidas em câmara úmida, com uso de nebulizadores por cinco dias.

Após a aclimatização, as mudas foram transferidas para bandejas plásticas de 24 células, contendo substrato estéril PlantiMax (horticultura), misturado a $2 \%$ da formulação 10-10-10, permanecendo por 21 dias em viveiro com sombrite $50 \%$.

A testemunha constituiu-se de 48 rizomas, coletados no próprio local do experimento, localizado no Lote 78 do Distrito de Irrigação do Baixo Açu, município de Alto do Rodrigues, Vale do Açu (RN).

À medida que os tratamentos foram sendo obtidos, realizou-se seu plantio em julho de 2001. Cada tratamento foi plantado em lotes, compostos por linhas contíguas em espaçamento de 3,5 × 2,20 m, os quais receberam individualmente adubação de plantio e os tratos culturais normais de manutenção do pomar, inclusive irrigação por microaspersão.

Não foi possível montar um delineamento experimental convencional, mesmo sem a inclusão de repetições, devido ao diferente número de plantas obtido de cada tratamento e a necessidade de realizar o plantio dentro de época apropriada.

As avaliações foram mensais e consistiram em observar planta por planta, no intuito de se encontrar algum tipo de variação morfológica.

Durante a avaliação, observaram-se características morfológicas variantes com relação à inserção das folhas no pseudocaule, formas da folha, variação da clorofila na folha, retardamento no desenvolvimento, interação dessas características e características gerais do cacho, como tamanho de dedo e número de pencas/cacho.

\section{RESULTADOS E DISCUSSÃO}

Ao término da fase de laboratório e aclimatização, formaram-se os sete tratamentos de gerações de plantas obtidas através de $3,4,5,6,7,8$ e 9 subcultivos, com total de 426 plantas da cv. Pacovan, como demonstra a Tabela 1.

Após as diversas avaliações, os seguintes tipos de variantes somaclonais foram identificados:

1. Variante de Cacho (VC) - caracteriza-se por apresentar a planta com as propriedades morfológicas normais da cv. Pacovan, como altura da planta, coloração e forma das folhas e pseudocaule, exceto pela conformação do cacho. Nesse caso, o cacho da variante apresenta-se com número médio de cinco pencas/cacho e dedos da segunda penca com tamanho médio de $14,4 \mathrm{~cm}$, enquanto o controle apresenta cacho com número médio de oito pencas/cacho e dedos da segunda penca com tamanho médio de 22,1 $\mathrm{cm}$, normal para o primeiro ciclo de cultivo dessa cultivar irrigada. O menor número de pencas / cacho e o tamanho reduzido dos dedos com conseqüente diminuição da massa, em média de $26 \%$, faz com que esse cacho seja classificado como de segunda, tendo pouco valor comercial e acarretando prejuízo ao agricultor.

2. Variante Variegada (VV) - caracteriza-se por apresentar variegações em todas as partes da planta, das folhas ao pseudocaule incluindo o cacho. A produção é inexpressiva, uma vez que o cacho apresenta tamanho reduzido e danos por queimadura solar devido a pouca clorofila existente na planta. Os descendentes apresentam o mesmo tipo de variegação dessa planta que revela potencial para ornamentação. 
Tabela 1.Variantes somaclonais encontrados nas diferentes tratamentos da cultivar Pacovan no Vale do Açu (RN), em 2002

\begin{tabular}{|c|c|c|c|c|c|c|c|}
\hline \multirow{2}{*}{ Tratamentos } & \multicolumn{3}{|c|}{ Plantas observadas } & \multicolumn{4}{|c|}{ Tipos de variantes somaclonais } \\
\hline & Total & Normal & Variantes & $\mathrm{VC}$ & VV & VMFF-VCF & $\mathrm{VCP}$ \\
\hline & \multicolumn{3}{|c|}{$\%$} & \multicolumn{4}{|c|}{$\%$} \\
\hline Controle & 48 & $48(100)$ & 0 & 0 & 0 & 0 & 0 \\
\hline F3 & 11 & $11(100)$ & 0 & 0 & 0 & 0 & 0 \\
\hline F4 & 16 & $16(100)$ & 0 & 0 & 0 & 0 & 0 \\
\hline F5 & 31 & $31(100)$ & 0 & 0 & 0 & 0 & 0 \\
\hline F6 & 41 & $39(95,20)$ & $2(4,80)$ & $1(2,40)$ & 0 & 0 & $1(2,40)$ \\
\hline F7 & 65 & $63(96,93)$ & $2(3,07)$ & $2(3,07)$ & 0 & 0 & 0 \\
\hline F8 & 90 & $86(95,52)$ & $4(4,48)$ & $2(2,24)$ & $1(1,12)$ & $1(1,12)$ & 0 \\
\hline F9 & 172 & $162(94,20)$ & $10(5,80)$ & $6(3,48)$ & 0 & $2(1,16)$ & $2(1,16)$ \\
\hline
\end{tabular}

$\mathrm{VC}=$ variante de cacho. $\mathrm{VV}$ = variante variegada. $\mathrm{VMFF}-\mathrm{VCF}$ = variante morfológica da forma da folha e clorofila da folha. $\mathrm{VCP}=$ variante da coloração do pseudocaule.

3. Variante Morfológica da Forma da Folha associada a uma Variação da Clorofila na Folha (VMFF - VCF) - caracteriza-se pelo estreitamento do limbo foliar com um afilamento pronunciado na ponta da folha, deixando-a com forma lanceolada. Associada a essa característica, um dos lados da folha, geralmente o direito para quem vê a folha pela face inferior, é menor e com variegações acompanhando toda a extensão de sua borda. Em sua face superior, podem ser observadas pequenas manchas de coloração negra semelhante a queimaduras. A extremidade da borda que circunda toda a folha é ligeiramente mais grossa, dando um aspecto serrilhado a essa estrutura. A área foliar é menor que uma folha de planta normal.

4. Variante da Coloração do Pseudocaule (VCP) - caracteriza-se por apresentar coloração negra e brilhante no pseudocaule, acompanhando o engaço em tom opaco até chegar nas flores. Fica bem evidente a diferença da coloração quando comparada ao controle que possui tonalidade verde-clara e opaca.

Pela Tabela 1 verificam-se os tipos de variantes encontrados e a porcentagem de variação somaclonal total para cada tratamento estudado na cv. Pacovan. Observa-se que até em 5 subcultivos (F5) não houve a ocorrência de variantes e que a partir do $6 .^{\circ}$ subcultivo (F6) foram detectadas variantes $(4,8 \%)$, atingindo o máximo de 5,8\% em nove subcultivos (F9).

A variante mais comum encontrada foi do tipo VC, que apresentou modificações morfológicas no cacho. Os tipos de variantes classificados como VMFF-VCF e VCP, estudados no presente trabalho, foram também observados por SMITH (1988) e RoDRIGUES et al (1998), na caracterização de variantes somaclonais em mudas de bananeira in vitro.
O aumento da porcentagem da variação somaclonal, em vista do número de subcultivos, foi relatado também por Scowcroft (1984) e GEORGE e SHERRINGTON (1984), sendo um dos fatores responsáveis pela ocorrência de anomalias em plantas micropropagadas. Tais resultados mostram que as biofábricas devem ter um total controle desse parâmetro, pois como demonstrou YuYLSTEKE (1996), a maioria das variantes apresentaram desempenho inferior ao de uma planta normal.

Os resultados do presente trabalho revelam que para obtenção de mudas de bananeira da cv. Pacovan com qualidade genética deve-se micropropagar um ápice caulinar até cinco subcultivos.

A mesma preocupação foi demonstrada por KRIKORIAn et al. (1993), no controle do número de subcultivos, para a manutenção da qualidade da muda. Para Reuveni et al. (1986) o número de plantas obtidas a partir de um ápice caulinar de uma triplóide AAA, não deve ultrapassar a 1.000 plantas, mantendo-se assim a qualidade genética da muda micropropagada.

Deve-se ressaltar que Rodrigues et al (1998), trabalhando com a cv. Nanicão, obtiveram resultado semelhante com relação à influência do número de subcultivos e o aumento da taxa de variação somaclonal, recomendando até sete subcultivos para essa cultivar. No presente trabalho, apesar de indicar a mesma tendência de aumento da variação somaclonal em vista do número de subcultivos, fica demonstrado que a cv. Pacovan (AAB) possui um comportamento in vitro diferente da cv. Nanicão (AAA). Enquanto na cv. Nanicão as variantes aparecem a partir 
de nove subcultivos (Rodrigues et al, 1998), na cv. Pacovan, no sexto subcultivo, ocorre o aparecimento de plantas indesejáveis na porcentagem de $4,8 \%$, chegando a $5,8 \%$ no nono subcultivo, taxa superior quando comparada à $\mathrm{cv}$. Nanicão, que apresentou 2,2\% também no nono.

Além de diferentes taxas de variação somaclonal entre as cultivares, observaram-se tipos de variantes que não foram encontrados na cv. Nanicão, bem como variantes dessa cultivar também não encontradas na 'Pacovan'. A variante VC, mais comum para a cv. Pacovan, não ocorre na 'Nanicão' e a VMIF (Variante Morfológica da Inserção da Folha no Pseudocaule), típica da triplóide AAA Nanicão (RodRIGUes et al., 1998) não ocorre na triplóide AAB Pacovan. Portanto o genótipo utilizado deve ser considerado em trabalhos de micropropagação de bananeira, principalmente quando se visa à produção comercial de mudas.

Como na presente pesquisa, observou-se que os perfilhos apresentavam as mesmas características das variantes, excluiu-se então a possibilidade de outros fatores serem responsáveis pelas modificações encontradas. Apesar disso, os autores reconhecem que outros testes (análise molecular) podem ser realizados para a comprovação final. Os estudos revelam o risco que corre o agricultor ao plantar mudas micropropagadas, adquiridas de biofábricas que não observem as condições adequadas para micropropagação, incluindo o número de subcultivos, pois pode haver alta porcentagem de variantes somaclonais, comprometendo não somente a primeira colheita.

\section{CONCLUSÕES}

1. A porcentagem de variação somaclonal aumenta com o número de subcultivos e, portanto, as biofábricas devem limitar o número de subcultivos para obtenção de mudas de alta qualidade genética.

2. Para cada cultivar de bananeira deve-se aplicar um procedimento diferenciado no processo de micropropagação, considerando os diferentes genótipos, a fim de se evitar alterações na qualidade genética da muda.

\section{AGRADECIMENTOS}

Os autores agradecem a CAPES pela concessão das bolsas aos autores, ao Distrito de Irrigação do Baixo Açu (DIBA) - RN, pela cessão de área experimental e a BioCampo Biotecnologia Agrícola Ltda., pelo apoio técnico na produção das mudas.

\section{REFERÊNCIAS}

GEORGE, E.F.; SHERRINGTON, P.D. Plant propagation by tissue culture. In: EXEGETICS. Handbook and directory of commercial laboratories. London: Exegetics, 1984. p.51-78.

$\mathrm{KARP}, \mathrm{A}$. Origins, causes and uses of variation in plant tissue cultures. Plant Cell Tissue and Organ Culture, Dordrecht, v.7, p.139-151, 1994.

KRIKORIAN, A.D.; IRRIZARRY, H.; CRONAUER, S.; RIVERA, E. Clonal fidelity and variation in plantain (Musa AAB) regenerated from vegetative stem and floral axis tips in vitro. Annals of Botany, New York, v.71, p.519-535, 1993.

MURASHIGE, T.; SKOOG, F. A revised medium for rapid growth and bio assays with tabacco tissue culture. Physiologia Plantarum, Copenhagen, v.15, p.473-497, 1962.

REUVENI, O.; ISRAELI, Y.; DEGANI, H.; ESHDAT, Y. Genetic variability in banana plants multiplied via in vitro techniques. In: INTERNATIONAL BOARD FOR PLANT GENETIC RESOURCES MEETING, 1986, Rome. Resumos... Rome: IBPGR, 1986. p.36.

RODRIGUES, P.H.V.; TULMANN NETO, A.; CASSIERI NETO, P.; MENDES, B.M.J. Influência do número de subcultivos na ocorrência de variação somaclonal em mudas de bananeira cv. Nanicão, no Vale do Ribeira - SP. Revista Brasileira de Fruticultura, Jaboticabal, v.20, n.1, p.74-79, 1998.

SCOWCROFT, W.R. Genetic variability in tissue culture, impact on germplasm conservation and utilization. In: INTERNATIONAL BOARD FOR PLANT GENETIC RESOURCES MEETING, 1986, Rome. Resumos... Rome: IBPGR, 1984. p.41.

SMITH, M.K. A review of factors influencing the genetic stability of micropropagated bananas. Fruits, Paris, v.43, n.4, p.219-223, 1988.

STOVER, R.H. Somaclonal variation in Grande Naine and Saba bananas in the nursery and field. In: PERSLEY, G.J.; DELANGHE, E.A. (Eds.). INTERNATIONAL WORKSHOP ON BANANA AND PLANTAIN BREEDING STRATEGIES, 1986, Cairs. Proceedings... Cairs, 1987. p.136-139.

VUYLSTEKE, D.; SWENNEN, R.; DE LANGUE, E. Field performance of variants of plantain (Musa spp., AAB group). American Journal Society for Horticultural Science, Alexandria, v.121, n.1, p.42-46, 1996. 